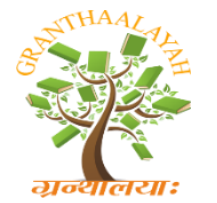

$$
\begin{gathered}
\text { INTERNATIONAL JOURNAL OF RESEARCH } \\
\text { GRANTHAALAYAH } \\
\text { A knowledge Repository }
\end{gathered}
$$

Management

\title{
FARM LEVEL EFFICIENCY OF RUBBER AS A PERENNIAL CROP USING COBB-DOUGLASS PRODUCTION FRONTIER
}

\author{
A. Aliyu ${ }^{* 1}$, B.A Shelleng ${ }^{1}$, J. Usman ${ }^{1}$ \\ ${ }^{1}$ Department of Agricultural Economics and Extension, Faculty of Agriculture, Adamawa State \\ University, Mubi, PMB 25 Mubi, Adamawa State, Nigeria
}

\begin{abstract}
This paper examines the parametric efficiency analysis of rubber production in Malaysia using Stochastic Frontier Analysis (SFA). The 3 different sample sizes used were 307, 206 and 101 for all-age, matured-age and old-age categories respectively. The results of the study reveals that the mean values of the rubber yield under all-age category was $3,638.28 \mathrm{~kg} / \mathrm{ha}$ while that of the matured-age and old-age categories 4,611.34kg/ha and 1,653.61kg/ha respectively. The Maximum likelihood estimates (MLE) results revealed that 5 independent variables were significant under all-age and matured-age categories while the old-age category has all the independent variables significant. With regards to elasticity of production for rubber task, $1 \%$ increase in number of rubber tree/ha leads to an increase in $0.76,0.70$ and 0.61 per cents in all-age, matured-age and oldage crop categories respectively. The coefficients values of the sigma squared for the all-age, matured-age and old-age were $0.14,0.26$ and 0.03 respectively, while the gamma values for the respective crops age categories stood at 1.00, 1.00 and 0.5 . The coefficients values of all-age crops category showed that 3 variables were statistically significant at $1 \%$ level of significance. 2 variables were having negative coefficients while the remaining 1 had positive coefficient. The mean technical efficiency scores for all-age, matured-age and old-age crops categories were found to be respectively $0.70,0.77$ and 0.72 . None of the crops age categories have farms on the frontier. The study concludes that Race and marital status were found to be very critical in determining efficiency of all-age crop category. Also, the matured-age crops are better than the other two cropage categories in terms of efficiency. Also, both the matured-age and the all-age crop categories are experiencing decreasing return to scale of the production process while the old-age category has an increasing return to scale production process. The study recommends downsizing some of the inputs especially farm size, fertilizer application rate as well as farm tools.
\end{abstract}

Keywords: Technical Efficiency; Stochastic Frontier Analysis; Cobb-Douglass; Production Frontier; Rubber and Malaysia.

Cite This Article: A. Aliyu, B.A Shelleng, and J. Usman. (2018). "FARM LEVEL EFFICIENCY OF RUBBER AS A PERENNIAL CROP USING COBB-DOUGLASS PRODUCTION FRONTIER." International Journal of Research - Granthaalayah, 6(7), 65-75. https:// doi.org/10.29121/granthaalayah.v6.i7.2018.1284. 


\section{Introduction}

\section{Rubber Production}

The production of rubber is normally termed "Tapping" or more clearly called "Rubber tapping" and this basically refers to a situation in which the rubber trunk or the back of a rubber tree is deliberately, systematically and in a controlled pattern, got wounded and subsequently milk-like liquid called "latex" oozes out in to an already attached collection cup. Depending on the taping system, the process occurs either daily or on alternate days with v-shaped or spirally-shaped cuts. Also depending on how fast and quick the accessible rubber tree trunk is re-generated, the tapping processes continue for about twenty (20) years, once it has commenced (Giroh et al, 2012). The collected milk-like latex liquids are emptied in to larger containers mixed with liquid ammonium to serve as anticoagulants (to prevent coagulation of latex) and then eventually driven to rubber factories where they are weighed, heat-dried and reweighed again to measure the $\mathrm{kg}$ of the dried rubber output ( Tran et al,1993).

\section{Stochastic Production Frontier (SFA)}

Stochastic Frontier Model which is one of statistical approaches, produces efficiency measures, while Data Envelopment Analysis (DEA) which is deterministic in nature, produces efficiency measures (Schmidt and Horrace, 1996). The process of estimating technical efficiency using the parametric or stochastic model requires two most important factors. These factors include the assumption of a particular functional form and also the inclusion of an additional error term in the production frontier to account for technical inefficiencies (Ogunniyi and Ajao, 2011).

There exist about three (3) popular functional forms used in estimating a particular production function. This include Cobb-Douglas, Transcendental Logarithmic (Translog) and Constant Elasticity of Substitution (CES). However, only two of the three functional forms have been widely used in recent literatures. Such two functional forms include the simplest Cobb Douglas Production Function and the relatively complex Transcendental Logarithmic technique (Coelli, 1998). It has been established that stochastic frontier models were initially and originally formulated by Aigner, Lovell and Schmidt (1977) and Meeusen and Van den Broeck (1988). Other similar models were later developed from the works of Olson et al (1980), Jondrow et al (1982), Pitt and Lee (1981) as well as Schmidt and Sickless (1984). Although the earlier work of Aigner (1977); Meeusen and Vanden Broeck (1988) were specifically on cross sectional data, but panel data analysis using the stochastic frontier model were also exploited. Schmidt and Sickless (1984) and Pitt and Lee (1981) were the first to explore panel data analysis. Recently the work of some authors such as Cornwell and Schmidt (1995), Greene (1995), Lovell (1993), Lovell and Schmidt (1988) and Battese and Coelli (1995) have critically looked at the panel data analysis.

However, an appreciable number of some research works that have also used cross section data in their analysis. Such can be viewed in the works of Kumbhakar et al (1991) and Relfschneider and Stevenson (1991).

\section{Materials and Methods}

\section{Study Area}

Negeri Sembilan is one of the 13 states in Malaysia and has a total land area of 6,641 square kilometers. The state consist of 9 districts including Seremban, Tanpin, Rembau, Kuala Pillah, 
Jempol, Jelebu, Rasah, Telok and Kemong. However, in this study only 5 districts including Seremban, Tanpin, Rembau, Kuala Pillah and Jempol were purposively selected due to their high concentration of rubber smallholders. Accordingly these 5 districts are believed to represent the Negeri Sembilan State fairly well. The state is located between Latitude $2^{\circ} 43^{\prime} 6.9312 \mathrm{~N}$ "and Longitude E $101^{\circ} 56$ 56.3564E" North and East of the Equator. It is bounded by Kuala Lumpur to the North and Pahang to the East. Melaka and Johor States were on its Southern part. It has an average annual temperature of $27.1^{\circ} \mathrm{C}$ and a mean annual precipitation of $1984 \mathrm{~mm}$. The state is well suited for the plantation farming such as oil palm, rubber and coconut plantations.

Below is a comprehensive map of Negeri Sembilan State where the research work was carried out.

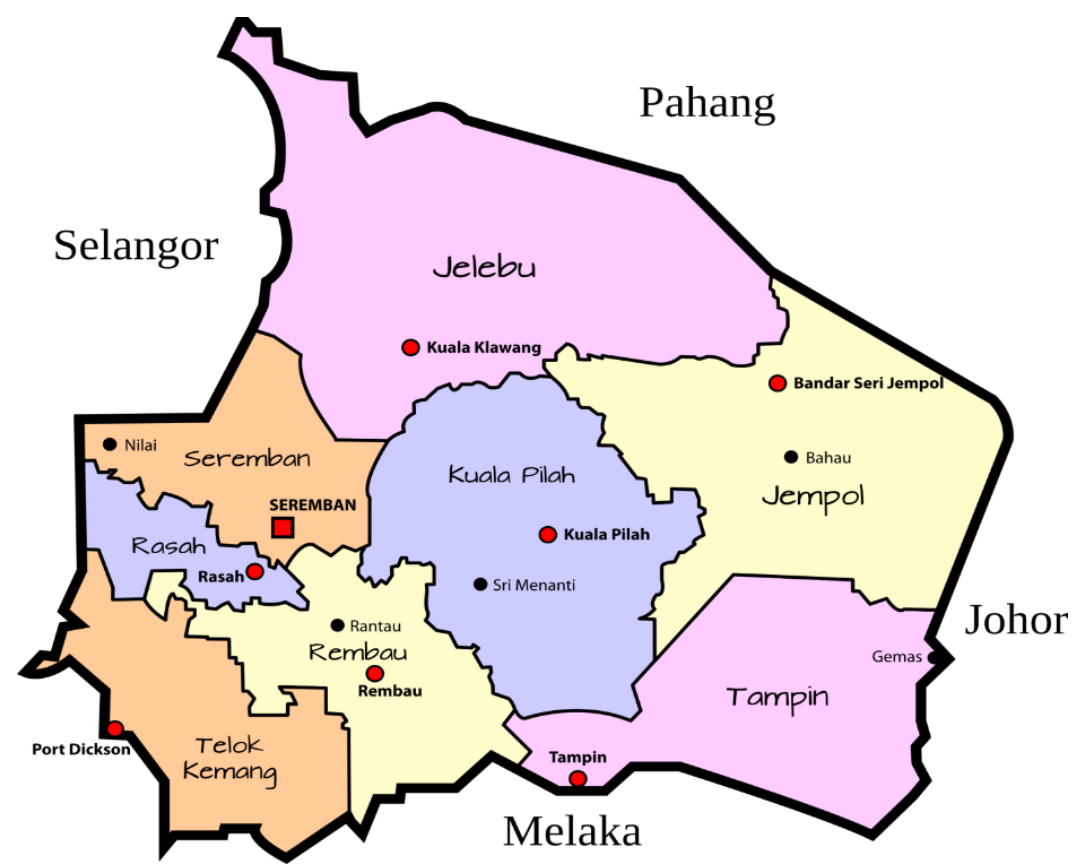

Figure 1: Map of Negeri Sembilan showing Various Districts and towns

\section{Sampling Procedure}

The data for the study was collected within 2-3 months using a multistage sampling procedure. In the first stage, 5 districts of Seremban, Tampin, Rembau, Kuala Pilah and Jempol were selected considering the intensity of rubber area coverage among different districts. The second stage involved purposive selection of two villages from each of the five districts, making a total of ten (10) villages. The third selection was based on randomly selecting 35 respondents' farmers from each village, making a total of 350 smallholders. However, of the 350 questionnaires administered, 338 were retrieved for a total response rate of $96.6 \%$ and of the 338 returned questionnaires; 11 were carefully sorted and discarded due to incomplete information. Finally only 327 questionnaires were found to be useful for the research and hence formed the sample size of this study. Also, out of the 327 sample size realized, only 307 observations were used in computing inferential statistics, because the young-age category, which has 20 respondents, has been removed due to statistically scanty nature of the sample size. However, in computing the descriptive statistics analysis, the whole sample size of 327 observations was used. Therefore, in analyzing inferential statistics, 307, 206 and 101 number of smallholders under all-age, matured-age and old-age categories respectively were applied. 


\section{Analytical Technique}

Cobb-Douglas Production Functions (CD)

Cobb-Douglas production function is one of the simplest production functions among the models of Stochastic Frontier Analysis (SFA). It is expressed as shown below.

$\operatorname{Ln}(Y)=\beta O+\beta_{1} \ln \left(X_{1}\right)+\beta_{2} \ln \left(X_{2}\right)+\beta_{3} \ln \left(X_{3}\right)+\beta_{4} \ln \left(X_{4}\right)+\beta_{5} \ln \left(X_{5}\right)+\beta_{6} \ln \left(X_{6}\right)+(V i-U i)$

Where:

$\mathrm{Y}=$ Output ( $\mathrm{kg}$ of dry rubber) of the ith farm,

$\mathrm{X} 1=$ Tapping Area or land size (ha)

$\mathrm{X} 2=$ Rubber task $\left(\mathrm{ha}^{-1}\right)$

$\mathrm{X} 3=$ Farm tools

$\mathrm{X} 4=$ Fertilizer $(\mathrm{kg})$

X5 $=$ Chemical Herbicides $(1 /$ ha $)$

X6= Labor (man days)

$\mathrm{V}_{\mathrm{i}}=$ Random noise (white noise) which are $\mathrm{N}(0$, ó $\mathrm{v})$

$\mathrm{U}_{\mathrm{i}}=$ are inefficiency effects which are non-negative, half normal distribution $\mathrm{N}(0, \hat{2} 2 \mathrm{U})$

\section{Results and Discussions}

This section examined the socio-demographic profiles of the smallholders, inputs variables used, maximum likelihood estimates (MLE) of the Cobb-Douglas production frontiers.

\section{Socio-Demographic Characteristics of the Respondents}

Table I consist of the descriptive statistics of socioeconomic factors of each of the three (3) agecategories of the smallholder farms and one with wholesome or aggregated age category for comparison purpose. The 4 socio-economic characteristics were solely expressed in terms of frequency and percentages. Such variables include gender, race, marital status and educational level.

Gender variable $\left(Z_{1}\right)$ which was categorized into male and female was found to be having $52.3 \%$ males and $47.7 \%$ females. In terms of age group, Young-age group has seven (35\%) males and thirteen (65\%) Females; Matured-age group has $52.53 \%$ males and $47.57 \%$ female respondents while old-age group of rubber plantations has $55.44 \%$ males and $44.55 \%$ female smallholders. The second variable $\left(Z_{2}\right)$ is race and this was categorized into 4 sub-variables in accordance with ethnicity traits. These include Malay, Chinese, Indians and others. Out of the total sample of 327 respondents, $86.24 \%$ were Malay, $2.14 \%$ were Chinese, $0.61 \%$ were Indians and $11.0 \%$ respondents were from other racial backgrounds. Regarding age group, old-age group were mostly Malay respondents with only 1 Chinese and no Indian smallholder. Matured-age group have Malay comprising $79.6 \%$, Chinese, $1.94 \%$, $0.97 \%$ Indians and $17.48 \%$ from other race. The young-age category of the plantations recorded only Malay and Chinese but no Indian and no any other racial backgrounds. This group was also dominated by Malay with almost $90 \%$ while Chinese have approximately $10 \%$ respondents. The third socio-demographic variable is Marital Status $\left(\mathrm{Z}_{3}\right)$ and this was categorized in to 'single', 'married' and 'other'. "Single" means an individual or respondents that have never been in to marriage or matrimonial institution, while "married" means an individual or a respondent currently in marriage. And "Other" means an individual who was previously married but currently not married due to death, divorce and the likes. Out of the 327 
respondents partitioned in to 20, 206 and 101 number of individuals for the young-Age, MaturedAge and Old-age groups respectively, only 10 were single while 305 were married and this comprise about $93 \%$ of the sample size. The 305 married smallholder respondents were spanned over the three age groups with 17, 189 and 99 respectively for the young-age, matured-age and old-age groups for rubber farms.

Educational level which is the fourth socio-economic variable $\left(Z_{4}\right)$ is categorized in to four sub categories which include no education, primary, secondary and diploma levels of education. The highest number of the respondents was found to be secondary school leavers and followed by primary school which is the next highest with 163(49.85\%) and $125(38.23 \%)$ numbers of smallholders respectively. Only 7 respondents had diploma certificates and $32(9.79 \%)$ farmers had not attended school. Under young-age group all the 20 respondents attended school but only one (1) had diploma certificate. The remaining 6 (2.91\%) diploma holders belong to matured-age group. None of the old-age category had diploma certificate and 14(13.86\%) of them had not attended school. However, 39(38.61) and 48(47.52) attended primary and secondary schools respectively.

Table 1: Distribution of Socio-Demographic Profiles of Rubber Smallholders

\begin{tabular}{|l|l|l|l|l|}
\hline Variables & All Crops & Young Crops & Matured Crops & Old Crops \\
\hline Gender(Z1) & Freq (\%) & \multicolumn{1}{|c|}{ Freq (\%) } & \multicolumn{1}{|c|}{ Freq (\%) } & Freq (\%) \\
\hline Male & $171(52.30)$ & $7(35)$ & $108(52.43)$ & $56(55.44)$ \\
\hline Female & $156(47.70)$ & $13(65)$ & $98(47.57)$ & $45(44.55)$ \\
\hline Race(Z2) & & & & \\
\hline Malay & $282(86.24)$ & $18(90)$ & $164(79.61)$ & $100(99.01)$ \\
\hline Chinese & $7(2.14)$ & $2(10)$ & $4(1.94)$ & $1(00.99)$ \\
\hline India & $2(0.61)$ & $0(0)$ & $2(0.97)$ & $0(00.0)$ \\
\hline Other & $36(11.0)$ & $0(0)$ & $36(17.48)$ & $0(00.00)$ \\
\hline Marital Status(Z3) & & & & \\
\hline Single & $10(3.06)$ & $1(5)$ & $8(3.88)$ & $1(0.99)$ \\
\hline Married & $305(93.27)$ & $17(85)$ & $189(93.5)$ & $99(98.02)$ \\
\hline Other & $12(3.67)$ & $2(10)$ & $9(4.37)$ & $1(0.99)$ \\
\hline Educational Level(Z4) & & & & $14(13.86)$ \\
\hline No & $32(9.79)$ & $0(0)$ & $18(8.74)$ & $39(38.61)$ \\
\hline Primary & $125(38.23)$ & $5(25)$ & $81(39.32)$ & $48(47.52)$ \\
\hline Secondary & $163(49.85)$ & $14(70)$ & $101(49.03)$ & $0(00.0)$ \\
\hline Diploma & $7(2.14)$ & $1(5)$ & $6(2.91)$ & \\
\hline
\end{tabular}

Source: Field Survey, (2015)

\section{Descriptive Statistics for the Variables Used in the Study}

Table 2, explained the descriptive statistics of variable inputs and output used by each of the 3 agecategories of the smallholder rubber crops in the study. The variables used include rubber yield $(\mathrm{kg} / \mathrm{ha})$ as the output variable, farm size (ha), number of rubber trees per ha which often called rubber task, farm tools, fertilizer (kg/ha), chemical herbicides (lit/ha) and labour (man days) as the six inputs variables. The table specifically contained the mean and standard deviations of all the six independent (input) variables and the single dependent (output) variable used by each rubber crop age. 
Starting with the first category of all-age crops which has the total sample size of 307 smallholders, the mean value of the total output in $\mathrm{kg} / \mathrm{ha}$ was found to be $3,638.28 \mathrm{~kg} / \mathrm{ha}$ of rubber. The average output of the matured-age category was estimated to be $4,611.34 \mathrm{~kg} / \mathrm{ha}$ while that of the old-age category was found to be $1,653.61 \mathrm{~kg} / \mathrm{ha} / \mathrm{yr}$. This is an indication that the rubber latex has increased from more productive stage (matured-age category) and then declined to a relatively less productive stage (old-age category). That is less quantity of latex would be tapped from old rubber trees than the matured-age category. So the yield and ages of perennial crops would always take a parabola shapes when plotted.

The average farm size of the all crops was approximately 1.28 ha which has an average of 502 rubber plants on the farm. The mean fertilizer applied on the all-age crops was $382 \mathrm{~kg} / \mathrm{ha}$ while the average chemical herbicides used was recorded to be 13lit/ha. For the matured-crops, the average farm size was found to be 1.19 while the other variable inputs such as rubber task, fertilizer, herbicides were respectively estimated as $532,356 \mathrm{~kg} / \mathrm{ha}$ and $12.66 \mathrm{lit} / \mathrm{ha}$. The old-age crop category has its respective rubber task, chemical fertilizer and herbicides as $441 / \mathrm{ha}, 434 \mathrm{~kg} / \mathrm{ha}$ and 12.28lit/ha. The reason behind the difference between rubber yield ( $\mathrm{kg} / \mathrm{ha})$ of the matured-age and old age categories could be attributed to the effective utilization of the variable inputs. For instance, the average number of rubber trees of the matured -age was 532 which are higher than that of oldage which has only 441 trees per hectare. Although the amount of chemical herbicides were apparently the same in volume but the average quantity of fertilizer differs with the old-age has excess quantity of fertilizer than the matured-age crops. The fertilizer might have been excessively applied. This is because old-age crops have enough nutrients trapped through long years of nitrogen fixation. So applying more quantity of fertilizer to the soil will turn out to be more toxic to the plants and this has negative effect of reducing the yield.

Table 2: Statistics of the Variables Used in the Study

\begin{tabular}{|l|l|l|l|l|l|l|}
\hline \multicolumn{1}{|c|}{ Variables } & \multicolumn{2}{|c|}{ All Crops } & \multicolumn{1}{c|}{ Matured Crops } & \multicolumn{2}{c|}{ Old Crops } \\
\hline & \multicolumn{1}{c|}{ Mean } & \multicolumn{1}{c|}{ SD } & \multicolumn{1}{c|}{ Mean } & \multicolumn{1}{c|}{ SD } & \multicolumn{1}{c|}{ Mean } & \multicolumn{1}{c|}{ SD } \\
\hline Yield (kg/ha/yr.) & 3638.28 & 2899.88 & 4611.34 & 2913.36 & 1653.61 & 1550.47 \\
\hline Farm size(ha) & 1.26 & 0.60 & 1.19 & 0.48 & 1.40 & 0.77 \\
\hline Rubber Task(per ha) & 502.09 & 250.91 & 532.03 & 292.44 & 441.01 & 108.19 \\
\hline Farm Tools & 2.85 & 1.78 & 2.34 & 1.60 & 3.89 & 1.68 \\
\hline Fertilizer (kg/ha/yr.) & 381.76 & 317.72 & 356.35 & 298.57 & 433.59 & 349.45 \\
\hline Herbicides (lit/ha/yr.) & 12.53 & 8.68 & 12.66 & 9.44 & 12.28 & 6.91 \\
\hline Labour(man days) & 12.85 & 2.27 & 13.14 & 2.03 & 12.27 & 2.61 \\
\hline
\end{tabular}

\section{Maximum Likelihood Estimates (MLE) of Cobb-Douglas Production Frontier}

Table 3 displays the estimated coefficients results of the maximum likelihood estimation (MLE) of the Cobb-Douglas production frontier for the three crops' age categories of rubber smallholders. As explained earlier, these crop-age categories have sample sizes of 307,206 and 101 smallholders for all crops, matured-crops and old-crops respectively. The same 6 variables inputs were used on each of the crops age categories and the results are presented as shown in the table for comparison. The all-age crop category is regarded as the aggregated crop while that of the matured and old-age categories are termed as the disaggregated crops. The table also revealed that 5 of the 6 independent variables were statistically significant under all-age and matured-age categories, with only the chemical herbicides was not significant variable. The old-age category has all the 
independent variables statistically significant. Two variables were found to share common properties of being positively significant to all the 3 crops age categories of the smallholders. Such two variables are rubber task and labour. This indicates that these two variables were positively and statistically significant under each of the 3 crops' age categories. The positive coefficient sign of the two variables means that there is a direct relationship with the rubber yield.

With regards to elasticity of production for rubber task (i.e number of rubber trees per hectare), one percent increase in rubber tree would lead to an approximately the same (1\%) percent increase in rubber latex production yield of each of the crops age categories. More clearly, one percent increase in number of rubber tree per hectare leads to an increase of $0.76,0.70$ and 0.61 percent in all-age, matured-age and old-age crop categories respectively. Also looking at constant variable parameter $(\beta 0)$, it would be understood that the coefficient of elasticity for all-age, matured-age and old-age crops are 1.64, 1.71 and 0.97 respectively. Therefore by comparison, matured-age crop has higher coefficient of efficiency followed by all-age crops and then old-age crop category. This is an indication that the matured-age crops are better than the other two crop-age categories in terms of efficiency.

Also looking at the laws of returns to scale, the summations of coefficients of each crop age category revealed that the all-age crop category has 0.50 ; the matured-age category has 0.47 while the old-age crop category has 1.52. That means both the matured-age and the all-age crop categories are experiencing decreasing return to scale of the production process while the old-age category has an increasing return to scale production process. The implication here is that the output or yield of rubber latex of both the all-age crops and the matured-age crops will decrease when their respective set of inputs increase. That means there is no point of making any further production process since when inputs are increased, output tends to decline. Therefore, some strategic steps need to be taken at this juncture. Such steps could probably be to downsize some of the inputs especially farm size, fertilizer application rate as well as farm tools. This will definitely help to reduce the scale of production through cutting down some inputs of the all-age and matured-age crops. However, the old-age crops have return to scale of approximately 1.52. Therefore, with this magnitude of coefficient of elasticity, it translates that increasing the variable inputs during production process, the yield or rubber output will also increase. This means that there is still sufficient, adequate and enough room space for increasing production as well as improvement in productivity in the rubber smallholdings.

Table 3: MLE of the CD Production Frontier for all the 3 Crop Ages.

\begin{tabular}{|l|l|l|l|l|l|l|l|}
\hline Variables & Parameter & \multicolumn{2}{|c|}{ All-Crops } & \multicolumn{2}{c|}{ Matured Crops } & \multicolumn{2}{c|}{ Old Crop } \\
\hline & & Coeff. & T-ratio & Coeff. & T-ratio & Coeff. & T-ratio \\
\hline Constant & $\beta 0$ & 1.64 & $2.86 * * *$ & 1.71 & $3.32 * * *$ & 0.97 & $1.92 *$ \\
\hline Farm Size(ha) & $\beta 1$ & -0.48 & $2.74 * * *$ & -0.44 & $2.89 * * *$ & -0.26 & $1.72 *$ \\
\hline Rubber task & $\beta 2$ & 0.76 & $2.35 * * *$ & 0.70 & $2.07 * * *$ & 0.61 & $3.24 * * *$ \\
\hline Farm tools & $\beta 3$ & -0.17 & $3.11 * * *$ & -0.17 & $2.48 * * *$ & -0.22 & $2.93 * * *$ \\
\hline Fertilizer(kg/ha) & $\beta 4$ & -0.15 & $2.09 * * *$ & -0.08 & $1.98 * *$ & -0.33 & $2.57 * * *$ \\
\hline Herbicides(lit/ha) & $\beta 5$ & 0.03 & 1.27 & 0.03 & 1.24 & 0.23 & $1.88^{*}$ \\
\hline Labour(man days & $\beta 6$ & 0.51 & $2.65 * * *$ & 0.43 & $2.97 * * *$ & 1.49 & $2.68 * * *$ \\
\hline
\end{tabular}

Source: Field Survey (2015) 
Note:

$1 \%$ level of significance $=* * *$

$5 \%$ level of significance $=* *$

$10 \%$ level of significance $=*$

\section{Estimates of the Inefficiency Model of the Cobb-Douglas Production Frontier}

Table 5 captures the summary results of the inefficiency model of the Cobb-Douglas production frontiers of the 3 crop-age categories of rubber smallholders. The table vividly presents the coefficient and t-ratios of each of the crops-age categories. Four socio-demographic variables were presented in the first column of the table as shown. The table also shows the variance parameters of sigma squared, gamma values, Log Likelihood Function and Likelihood Ratio (LR) Tests for each of the 3 crops age categories of the rubber smallholders. Both the sigma squared and gamma values of each crops-age category were found to be statistically different from zero at $1 \%$ level of significance. The coefficients values of the sigma squared for the 3 different crop-age categories of all-age, matured-age and old-age are $0.14,0.26$ and 0.03 respectively, while the gamma values for the respective crops age categories stood at $1.00,1.00$ and 0.51 . The statistically significant nature of the variance parameter is an indication of goodness of fit and assumption that the distributional form of the composite error term was correct. The gamma variable specifically explains the total variation in output or dependent variable that is attributable to the technical efficiency. This means that the percentage of discrepancies between the frontier output and the observed output, or the technically efficient output and the actual output were due to technical inefficiency. Therefore, the gamma values of 1.00, 1.00 and 0.51 for all-age, matured-age and oldage crops categories respectively, simply means that $100 \%, 100 \%$ and $51 \%$ of the variations in rubber yield among smallholders were due to disparities in technical efficiencies. The column of the table containing the coefficients values of all-age crops category shows that 3 variables were statistically significant at $1 \%$ level of significance, 2 variables were having negative coefficients while the remaining one variable had positive coefficient. Race and marital status were found to be very critical in determining efficiency of all-age crop category of rubber smallholders.

Table 4: Estimates of the Inefficiency Model of the Cobb Douglas Production Functions

\begin{tabular}{|l|l|l|l|l|l|l|}
\hline Variables & \multicolumn{2}{|c|}{ All-Crops } & \multicolumn{2}{c|}{ Matured Crops } & \multicolumn{2}{c|}{ Old Crop } \\
\hline & Coeff. & T-ratio & Coeff. & T-ratio & Coeff. & T-ratio \\
\hline Constant & -0.84 & -1.46 & -0.36 & -0.42 & -0.20 & -0.32 \\
\hline Gender & 0.09 & 1.43 & 0.28 & $2.99 * * *$ & 0.03 & 0.57 \\
\hline Race & -0.38 & $-3.44 * * *$ & -0.37 & $-2.62 * * *$ & 0.06 & 0.24 \\
\hline Marital Status & 0.88 & $2.90 * * *$ & 1.57 & $4.14 * * *$ & 0.92 & $2.76 * * *$ \\
\hline Level of Education & -0.15 & $-2.01 * * *$ & -0.78 & $-4.52 * * *$ & -0.06 & -0.78 \\
\hline Variance Parameter & & & & & & \\
\hline Sigma Square & 0.14 & $6.89 * * *$ & 0.26 & $4.69 * * *$ & 0.03 & $5.02 * * *$ \\
\hline Gamma & 1.00 & $626.59 * * *$ & 1.00 & $1247.95 * * *$ & 0.51 & $3.69 * * *$ \\
\hline LLF & & 48.39 & & 68.21 & & 38.01 \\
\hline
\end{tabular}

Source: Field Survey (2015)

Note:

$1 \%$ level of significance $=* * *$

$5 \%$ level of significance $=* *$

$10 \%$ level of significance $=*$ 


\section{Estimates of Efficiency Scores for CD for the Three Crops' Age}

Table 5 estimates the range of scores, frequencies and percentages of efficiency scores of all the three different crops age categories under Cobb-Douglas production frontier analysis of the rubber smallholders. The mean technical efficiency scores for all-age, matured-age and old-age crops categories were found to be respectively $0.70,0.77$ and 0.72 . None of the crops age categories had farms on the frontier. However, 107 farms were found to possess efficiency scores more than 0.90 under all-age crops category, and this accounts for approximately $35 \%$ of the total number of farms under the all-age category. The number of farms that have scores more than 0.90 under maturedage crops category and old-age crops categories were found to be 104 and 11 farms respectively and their corresponding percentages are approximately $51 \%$ and $10 \%$ respectively. Going by both the percentage and average efficiency scores, it would be clearly seen that matured-age crops category has higher and better efficiency than the all-age and old-age categories. This could also be clearly seen from the figures of the mean technical efficiency of matured-age crops which is 0.77 and also more than $50 \%$ of the number of farms have attained scores greater than 0.90 . The maximum efficiency scores attained by each of the crop age categories is 0.99 while their respective minimum scores were recorded as $0.17,0.17$ and 0.51 for all-age, matured-age and oldage categories respectively.

The mean technical efficiencies of $0.70,0.77$ and 0.72 for the 3 age-categories translates that about $30 \%, 23 \%$ and $28 \%$ respectively for the all-age, matured-age and old-age crops are accounted for inefficiency.

Table 5: Estimates of Efficiency Scores for CD for the Three Crops' Age

\begin{tabular}{|l|l|l|l|}
\hline T.E Range & All Crops Freq.(\%) & Matured Crops Freq.(\%) & \multicolumn{1}{|c|}{ Old Crops Freq.(\%) } \\
\hline$<=20$ & $1(0.33)$ & $1(0.49)$ & $0(0.00)$ \\
\hline $0.21-0.30$ & $0(0.00)$ & $0(0.00)$ & $0(0.00)$ \\
\hline $0.31-0.40$ & $8(2.61)$ & $7(3.40)$ & $0(0.00)$ \\
\hline $0.41-0.50$ & $94(31.61$ & $47(22.82)$ & $0(0.00)$ \\
\hline $0.51-0.60$ & $31(10.10)$ & $9(4.37)$ & $7(6.93)$ \\
\hline $0.61-0.70$ & $20(6.52)$ & $5(2.43)$ & $56(55.45)$ \\
\hline $0.71-0.80$ & $15(4.89)$ & $12(5.83)$ & $17(16.83)$ \\
\hline $0.81-0.90$ & $31(10.10)$ & $21(10.19)$ & $10(9.90)$ \\
\hline $0.91-0.99$ & $107(34.85)$ & $104(50.49)$ & $11(10.89)$ \\
\hline 1 & $0(0.00)$ & $0(0.00)$ & $0(0.00)$ \\
\hline Summary & & & \\
\hline Mean & 70 & 0.77 & 0.72 \\
\hline S.D & 0.22 & 0.23 & 0.11 \\
\hline Max & 0.99 & 0.99 & 0.99 \\
\hline Min & 0.17 & 0.17 & 0.51 \\
\hline
\end{tabular}

Figure I presents Bar Chart efficiency for the 3 crops age categories using Cobb-Douglas production methods. The figure indicates no bar on the 1.00 range of scores and this translates that there is no single farm that is found on the frontier. However, 2 longest of bars representing allcrops and matured-crops were found on scale range of 0.91-0.99. This simply means that more than 100 numbers of farms under both the all-age and matured-age categories were having scores range of 0.91-0.99. 


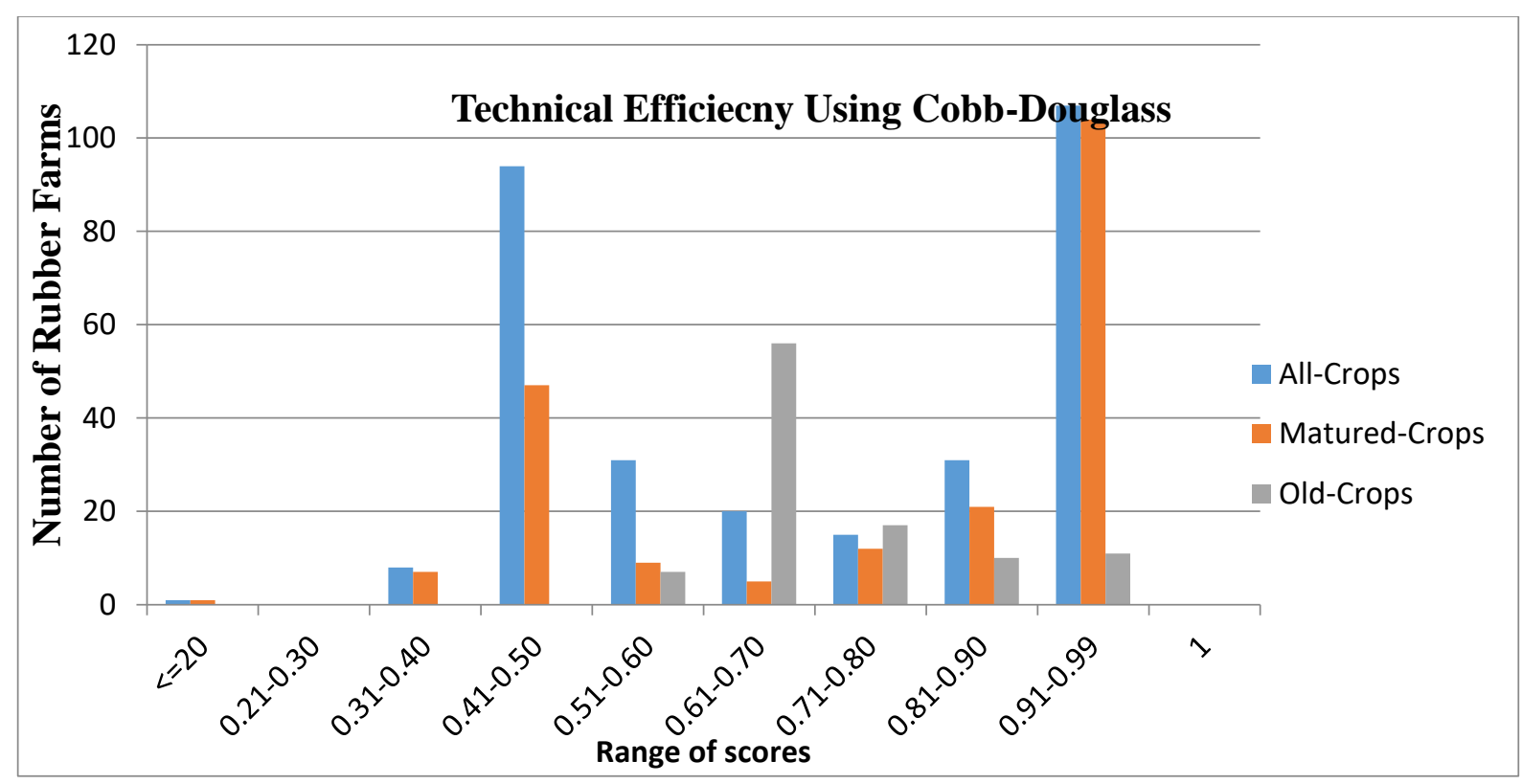

Figure I: TE of Rubber Age Categories Using Cobb-Douglas

\section{Conclusion}

The study concludes that the rubber latex has increased from more productive stage (matured-age category) and then declined to a relatively less productive stage (old-age category). This means less quantity of latex would be tapped from old rubber trees than the matured-age category. The reason behind this could be attributed to the effective utilization of the variable inputs.

With regards to elasticity of production for rubber task, $1 \%$ increase in number of rubber trees per hectare leads to an increase in $0.76 \%, 0.70 \%$ and $0.61 \%$ in all-age, matured-age and old-age crop categories respectively. Therefore, by comparison, matured-age crop has higher coefficient of elasticity followed by all-age crops and then old-age crop category. This is an indication that the matured-age crops are better than the other two crop-age categories in terms of efficiency.

Looking at the laws of returns to scale, both the matured-age and the all-age crop categories were experiencing decreasing return to scale of the production process while the old-age category had an increasing return to scale production process. The implication here is that the yield of rubber of both the all-age crops and the matured-age crops will decrease when their respective set of inputs increase. That means there is no point of making any further production process since when inputs are increased, output tends to decline.

Therefore, the study thus, recommends downsizing some of the inputs especially farm size, fertilizer application rate as well as farm tools".

\section{References}

[1] Aigner, D. J. Lovell, C. A. K. and Schmidt, P. (1977). "Formulation and Estimation of Stochastic Frontier Production Function Models", Journal of Econometrics, 6, 21-37. 
[2] Battese, G. E., \& Coelli, T. J. (1995). A Model for Technical Inefficiency Effects in A Stochastic Frontier Production Function for Panel Data. Empirical Economics, 20(2), 325-332.

[3] Coelli, T. (1998). A Multi-Stage Methodology for the Solution of Orientated DEA Models. Operations Research Letters, 23(3), 143-149.

[4] Cornwell, C., \& Schmidt, P. (1995). Production Frontiers and Efficiency Measurement. In the Econometrics of Panel Data (Pp.845-878). Springer Netherlands.

[5] Giroh, D.Y., Moses, J.D., \&Yustus,F.S(2012).Technical Efficiency and Cost of Production Among Small Holder Farmers in Edo State, Nigeria. World Rural Observations 3(3)

[6] Greene, W. H. (1995). Frontier Production Functions. Handbook of Applied Econometrics, 2, 81166.

[7] Horrace, W. C., \& Schmidt, P. (1996). Confidence Statements for Efficiency Estimates From Stochastic Frontier Models. Journal of Productivity Analysis, 7(2-3), 257-282.

[8] Jondrow, J., Lovell, C. K., Materov, I. S., \& Schmidt, P. (1982). On The Estimation of Technical Inefficiency in the Stochastic Frontier ProductioFunction Model. Journal of Econometrics, 19(23), 233-238.

[9] Kumbhakar, S. C., Ghosh, S., \& Mcguckin, J. T. (1991). A Generalized Production Frontier Approach for Estimating Determinants of Inefficiency in US Dairy Farms. Journal of Business \& Economic Statistics, 9(3), 279-286.

[10] Lovell, C. K., \& Schmidt, P. (1988). A Comparison of Alternative Approaches to the Measurement of Productive Efficiency. In Applications of Modern Production Theory: Efficiency and Productivity (Pp. 3-32) Springer Netherlands.

[11] Lovell, C. K. (1993). Production Frontiers and Productive Efficiency. The Measurement of Productive Efficiency: Techniques and Applications, 3-67.

[12] Meeusen, W., \& Van Den Broeck, J. (1988). Efficiency Estimation From Cobb-Douglas Production Functions With Composed Error. International Economic Review, 435-444.

[13] Ogunniyi, L. T., \& Ajao, A. O. (2011). Measuring the Technical Efficiency of Maize Production Using Parametric and Non-Parametric Methods in Oyo State, Nigeria. Journal of Environmental Issues and Agriculture in Developing Countries, 3(3), 113.

[14] Olson, J. A., Schmidt, P., \& Waldman, D. M. (1980). A Monte Carlo Study of Estimators of Stochastic Frontier Production Functions. Journal of Econometrics, 13(1), 67-82.

[15] Pitt, M. M., \& Lee, L. F. (1981). The Measurement and Sources of Technical Inefficiency in the Indonesian Weaving Industry. Journal of Development Economics, 9(1), 43-64.

[16] Reifschneider, D., \& Stevenson, R. (1991). Systematic Departures From the Frontier: A Framework for the Analysis of Firm Inefficiency. International Economic Review, 715-723.

[17] Schmidt, P., \& Sickles, R. C. (1984). Production Frontiers and Panel Data. Journal of Business \& Economic Statistics, 2(4), 367-374.

[18] Trans,S V. H., Coelli, T., \& Fleming, E. (1993). Analysis of the Technical Efficiency Of State Rubber Farms in Vietnam. Agricultural Economics, 9(3), 183-201.

*Corresponding author.

E-mail address: abdualiyu14@ymail.com 